\section{Hans Balsiger, Keeper of Order in the Universe}

\begin{abstract}
When delegates arrive at the table to negotiate space science programmes for the European Space Agency they put science first - most of the time, as chairman Hans Balsiger tells Toby Chapman
\end{abstract}

When doing physics Hans Balsiger has his head in solar winds and comet tails, building mass spectrometers and launching them into the solar system (which is his laboratory). But he has another job, keeping his head while dealing with the very down-to-earth problems of being chairman of the Science Programme Committee (SPC) with the European Space Agency (Esa).

He has the look of a man who is ready to sort through a problem. Emerging from the dark and plasticized quiet of Bern University's physics corridors he is wearing slacks and a white shirt with no tie but

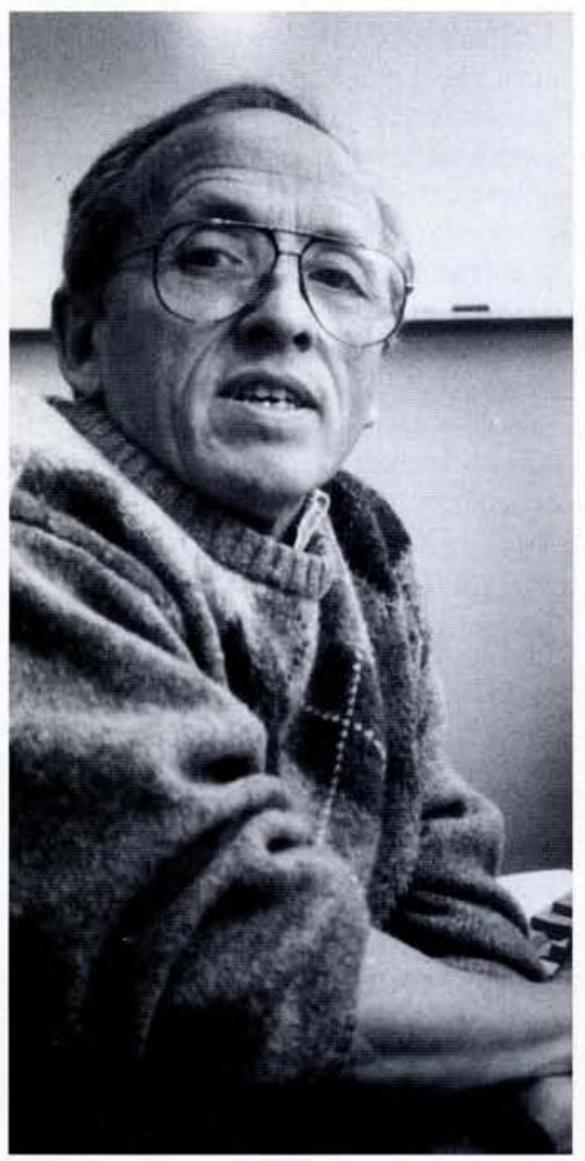

sleeves rolled up. On another person, rolled up sleeves might signal readiness for a fight. On Balsiger they seem to mean he's ready to listen, and to find a solution.

Which is fortunate, because there has been a lot to sort through at Esa recently. The fiery failure of Arianne 5 in June 1996 and the loss of the cornerstone Cluster mission has meant the whole science programme has had to be restructured, and done so during a budget freeze, a recent spell of cold economics that began in October 1995 .

The replanning is now mostly over. Cluster has been salvaged and will rise from its own ashes in three year's time aboard a Russian Soyuz clone. There remains only tidying up for the next SPC meeting in September at Oxford. So how does he feel, with the restructuring now behind him? He shrugs, 'How do I feel?' And looks puzzled by the question.

In addition to replanning, the SPC has had to quickly consider an express mission to Mars, proposed by Esa's science director Roger Bonnet. A new Mars mission would be very media friendly - the coverage of Nasa's recent Pathfinder Mars landing

\section{They of course say, "We were under pressure of money", but they skipped a few things which you cannot skip}

(with the first pictures of the Sojourner robot shown live on $\mathrm{CNN}$ ) is proof of that perhaps that's the driving force behind the mission? Balsiger has nothing against PR ('we need it desperately') but rejects the suggestion, pointing out that a Mars mission has always been a part of Esa thinking. 'We've always liked Mars, it's a fantastic planet. One has to explore it. It would be a pity if Europe were not involved. If people were not convinced that this is scientifically a very good thing to do, then no chance within this committee.'

The SPC stands between the group of eight space scientists who make up the Space Science Advisory Group at Esa and approval to fly for most science missions most science missions because there are also Earth observation and microgravity committees. The aim is to evenly spread measurement and experiment over different areas of space physics. Science is the only mandatory programme at Esa, which makes it Esa's backbone, and yet it consumes just $10 \%$ of Esa's total budget.

The Committee is democratic: the chairperson is elected and it's one member one vote when it comes to policy. Each of Esa's 14 member states sends a delegate to SPC meetings, of which there are at least three a year. David Southwood, Balsiger's predecessor in the chair, called one meeting a 'poker game'. Some delegates presumably go to each meeting with a hand prepared beforehand, ready to argue for the missions that favour their own scientists at home. Yet if they do, they don't play a ruthless game, insists Balsiger, they play like gentlemen.

'It's the least political program.

Everywhere else it's very much according to: "I have paid so much, I need to get that out again.” All the other programs [ie Earth observation, microgravity, Ariannespace] are à la carte programmes, and you pay as much as you want to get out.'

But with SPC 'it's science first'. Switzerland, Balsiger's home ground, Denmark and the Netherlands have hardly any space science programmes of their own. They're some of the small players. 'Whereas the big ones [eg United Kingdom, France, Germany], they have their own national programmes and sometimes they put the national interest on top of the European one. But this is done in a very sporty way; it is only very natural.'

This playful tension between member states is part of the democracy of the process. It slows down decisions because Esa has to get all 14 member states' representatives to a meeting before anything can be agreed. Nasa would have no such trouble. But then again, says Balsiger, Nasa isn't democratic. 'In the US, Committees produce their recommendations but Nasa pays for everything, and in the end money will say where things go. Whereas here in Europe we really can negotiate and try to have an optimum programme. And I like that very much.'

Since Esa has 14 masters, 'there's not just one science director who tells you what is happening, like

continued on page 138 